\title{
Patients' perception of the quality of nursing care and related hospital services
}

\author{
Mahmoud Al-Hussami ${ }^{*}$, Muwafaq Al-Momani ${ }^{2}$, Sawsan Hammad ${ }^{1}$, Mahmoud Maharmeh $^{1}$ and Muhamad Darawad $^{1}$ \\ ${ }^{1}$ School of Nursing, The University of Jordan, Amman-Jordan \\ ${ }^{2}$ Faculty of Nursing, Al-Hussien Bin Talal University, Maan-Jordan
}

\begin{abstract}
Background: Quality of care and related hospital services are core concern for healthcare providers and consumers that need improvement in Jordan and worldwide. Purpose: The study aims at exploring patients' perception of the quality of nursing care and related hospital services among Jordanian inpatients along with their intent to revisit the same hospital.
\end{abstract}

Methods: A descriptive design that utilizes cross-sectional survey was used to collect data through self-reported questionnaires. Eight Hospitals with more than 300 beds capacity were randomly selected from the four healthcare sectors in Jordan. Participants involved in this study were 148 of current patients admitted to hospitals in Jordan.

Results: The average reported perception level was 3.4/5 which considered low. The results of the Student's $t$ - test showed a statistically significant difference in scoring of quality of nursing care $(t(145)=8.001, P=0.000)$. Patients who have intent to revisit the hospital scored significantly higher $(M=3.72, S D=0.60)$ than patients who did not have intent to revisit the hospitals $(M=2.73, S D=0.75)$

Conclusion: Jordanian healthcare organizations have performed below the average in providing quality care, which considered significant to hospital administrators and directors of nursing.

Implications for nursing management: Hospital administrators and directors of nursing should be constantly implementing quality management in order to provide high quality services. Therefore, they need to focus more on patient satisfaction as an indicator for quality of care.

What is already known about the topic?: Patients have different criteria in evaluating nursing care.

1. Work environment has some effects on service quality.

2. Adequate nurse staffing is a key point to improve the quality of patient care.

3. Quality of care form nurses perspectives.

4. Little is known on how patients perceive nursing care.

What this paper adds?: Poor quality of nursing care and related hospital services was performed by healthcare institutions in Jordan as perceived by patients.

1. The quality of bedside nursing care is constantly affected by the related hospital services.

This study has important implications for hospital administrators and directors of nursing.

\section{Introduction}

The development of healthcare services is an important issue that depends on patient's perception of the quality of the received care [1]. Assessing the quality of services provided by nurses is crucial and, therefore, nurses are challenged to maintain and improve their quality of care [2]. Zhao and colleagues stated that the quality of nursing care is a core concern for healthcare providers and consumers that needs improvement, which makes satisfying consumers' needs an essential target. Further, Hoodless, et al. [3] considered the assessment of the quality of healthcare services to be part of a strategy that includes (1) meeting the basic standards such as performance, infrastructure, service delivery, and operational process; (2) consulting consumers; and (3) driving the quality of care by consumers where they are heard, listened to and involved in actual decision making. By measuring patient's perception, healthcare services regain essential information that can be used to improve the quality of nursing care and related hospital services [4]. Therefore, to build an image and maintain competitive advantages, the successful organizations recognize the significance of continuously delivering quality services [5].

Patients' perceptions of the received care have been found to contribute to the quality of care. Henoch, et al. [6] conducted a study to compare the views of both patients with lung cancer and their families with the quality of the provided care. A significant finding

Correspondence to: Mahmoud Al-Hussami, School of Nursing, The University of Jordan, Amman-Jordan, Tel: 0096265355000 Ext. 23138; Email: m.alhussami@ ju.edu.jo

Received: June 14, 2017; Accepted: July 15, 2017; Published: July 18, 2017 
of this study was that both patients and family members reported receiving low quality level of care. The study also found that there was a difference between patients' and their family members' ratings of the importance of different aspects of care, where family members were found to rate the importance of items about nursing care higher than what the patients did. The findings of this study were congruent with a qualitative study that interviewed 21 patients attending primary care clinics in Hong Kong [7]. The authors found that patients perceived both the process of the consultation and the outcomes of treatment to measure the quality of doctor's care. Interestingly, human skills such as smiling, being polite, and warm welcome were considered important for a comfortable atmosphere that facilitated the patient's ability to talk freely with their doctors.

Zhao, et al. [2] who conducted a study among 221 nurses and 383 patients in 18 non-ICU nursing units reported similar findings. The study aimed to explore and compare nurses and patients' perceptions of quality nursing care. Interestingly, both nurses and patients agreed that nursing care provided and received was of a high quality. However, nurses and patients had different views of quality nursing care. While nurses perceived that they provided a holistic nursing care, patients viewed that quality nursing care might have interfered with their privacy and sleeping time. Interestingly, Lee and Yom [8] found that patients were more satisfied with nursing care than their nurses were. Such difference in nurses and patients' views continued to emerge in literature. While nurses were found to value interpersonal aspect of caring, their patients valued higher nursing competency and skills [9].

Using phenomenology, Kvale and Bondevik [10] tried to gain insight about patient's perceptions of nurses' knowledge about cancer and its treatment related to quality of nursing care. Data consisted of in-depth interviews with 20 patients; most of them received lifeprolonging and symptom-relieving treatment. One of the most important finding emerged from the study was that nurses' knowledge about cancer and its related treatment with good technical skills were considered as important to alleviate patient's suffering and made them feel safe and secure. Further, patients mostly relied on experienced nurses rather than inexperienced. Such findings are in congruence with Issac, et al. [11] who found that the quality and safety of hospital services were related to the patient's experience with technical performance in the process of care, and that better patient experiences for each measure domain were associated with lower complications. Furthermore, Radwin, et al. [12] reported that patients acknowledged positive outcomes to nursing care, and that nurses who can help patients achieve desired outcomes are considered as knowledgeable and caring professionals.

In a study to explore the quality of nursing care in a primary care setting from the perspective of patients with leg ulcer, Tornvall and Wilhelmsson [1] found that patients were very satisfied with the standard of nursing care. Patients also perceived that nurses provided a high quality of nursing care. However, there were some areas that need improvement including increasing patient-centered care, continuity, and pain relief. These findings are similar to that of Riccio [13] who found that patients were generally satisfied with quality of nursing care. Interestingly, patients were found to be mostly satisfied with communication skills and the interdisciplinary collaboration between nurses and physicians. Moreover, they felt that nurses were good listener and spend time for providing information.

Another important determinant of the quality of healthcare services is patient's satisfaction [14]. In a study conducted to determine the client satisfaction with quality of nursing care in Jordan, patients were moderately satisfied with the quality of nursing care. Significantly, patients were found less satisfied with both coordination and interpersonal aspect of the care provided [15]. Furthermore, in a study conducted among 300 hospitalized patients in three different settings in Jordan, Alhusban and Abuarub [14] found that patient's satisfaction with nursing care was moderate. Looking at specific types of healthcare services, Darawad, Alhussami, et al. [16] reported that patients were only moderately satisfied with pain management services.

Yet, no study was found to assess Jordanian patients' perception of quality of nursing care and related hospital services. In Jordan, there is a growing interest by the healthcare institutions to enhance quality of patient care. In response to the current gaps in research evidence, this study aimed to explore patients' perceptions of the quality of nursing care and related hospital services among Jordanian inpatients along with their intent to revisit the same hospital.

\section{Methodology}

\section{Design}

A descriptive design that utilized cross-sectional survey was used to collect data through self-reported questionnaires from admitted patients in Jordanian hospitals.

\section{Settings}

According to Jordan Statistics Department [17] hospitals in Jordan are alienated in four categories, University hospitals $(\mathrm{n}=2)$, private hospitals $(n=61)$, governmental hospitals $(n=31)$, and military hospitals $(n=8)$. Eight Hospitals with a bed capacity greater than 300 were randomly selected from the four healthcare sectors in Jordan (two from each sector).

\section{Sampling}

The target population consisted of all admitted patients to Jordanian hospitals. After obtaining the approvals to carry out the research, permission to perform the research was obtained from the directors of the selected hospitals. The authors met the hospital directors, and informed them about the purpose of the study and invited their organizations to participate in the study by completing the questionnaire.

A non- probability convenience sampling technique was utilized to collect data from 148 patients admitted to different hospitals in Jordan. The inclusion criteria included patients who were at least 18 years old, have been admitted for at least 24 hours, have no mental or cognitive disorders, and can read and write Arabic language.

The sample size was calculated to obtain adequate power to detect differences between the scores of patients' preference to revisit the hospital and patients who had no preference to revisit the hospital. By using the program $G^{*}$ power analysis parameters [18] for the independent t-test, an estimated medium effect size of 0.50 , an alpha level of 0.05 (2-tailed), and power of 0.8 , a total of 128 participants from all selected hospitals is indicated. Additional twenty participants were recruited to overcome participants' incomplete questionnaires.

\section{Instrument}

The authors using individual items that were identified in earlier studies such as Senarath and Gunawardena [19] Lee and Yom [20] which is measuring the perception of admitted patients regarding the quality of nursing care and other related hospital services modified the questionnaire. The instrument is consisted of 36 items distributed 
among eight dimensions: interpersonal relationships between nurses and patients ( 12 items), efficiency in serving patients ( 7 items), comforts provided in the ward (4 items), sanitations (3 items), personalized information (3 items), physical environment in the ward (3 items), provision of general instructions by nurses ( 2 items), and competency of nurses in caring for patients ( 2 items). To establish content validity, a panel of five experts in the field of nursing reviewed the clarity and appropriateness of the linguistic of items, the suitability of items for each domain and in relation to the objectives of the study. Based on the feedback received, modifications were made and the questionnaire was returned to the experts for further examination.

The respondents (patients) were asked to evaluate the quality of nursing care and related hospital services in each item using a 5-point Likert scale ranging from 1 (dissatisfied/disagreed) to 5 (fully satisfied/ agreed). For each item, respondents were offered the option to indicate whether it was not relevant. Internal consistency reliability was calculated using Cronbach's Alpha Coefficient, which was 0.979 for the total scale, and ranged, for the subscales, between 0.927 (comforts provided in the ward) to 0.982 (physical environment in the ward).

The instrument was translated into the Arabic language using established guidelines for translation. A professional translator did translation of the scale from English to Arabic. A second translator back translated the Arabic version to English. Then, the original English version was compared with the back-translated English version. Moreover, a third party reviewed the translation. Pilot testing was conducted before running the actual study among 15 patients to evaluate the readability and comprehension of the scales.

\section{Ethical considerations}

Approval from the Scientific Research Committees at School of Nursing was obtained. In addition, approval from the Ethical Committee at each hospital management was obtained before the data collection begins to gain access to patients. Participation in this study was completely voluntary, and the researchers maintained the anonymity of the participants by recording no personal identifications. In addition, detailed information about the objectives of the study were contained in a cover letter attached to the questionnaire and the patient who agreed to participate, returned the questionnaire to the researchers. Filling the questionnaire was considered as an implied consent to participate in this study.

\section{Data collection procedure}

The package of this survey contained a cover letter and quality of nursing care questionnaire. After obtaining the ethical approval and one week prior to data collection, advertisements by trained research assistants were placed in the targeted institutions. These advertisements included the purpose of the study, the time needed, and the participants' role and rights. At the same time, data collectors (principle investigator and qualified data collector for that purpose) were attending a training session for one week to increase their capabilities in data collection, and to promote inter-rater reliability. Then, data collectors distributed the packages of self-reported questionnaires to patients in the targeted settings. Participants were instructed to return the completed questionnaire in a sealed envelope and gave it to the data collectors who were waiting in sites.

\section{Statistical analysis}

Based on the mentioned research aims, this quantitative crosssectional survey implemented a descriptive analysis plan and inferential statistical plan. This included frequency distribution, measures of central tendency, measures of dispersion, and Student's t-test.

\section{Results}

\section{Sample characteristics}

A total of 148 questionnaires were returned from patients at different hospitals' departments out of 250 with $60 \%$ response rate. Descriptive analyses were used to describe the sample characteristics, which revealed that the majority were females $(66 \%)$, had a diploma level of education (39\%), married (66\%), covered by a governmental insurance (66\%), and lived in countryside (53\%). In addition, the mean age of the participants was 33 years $(\mathrm{SD}=8.3)$, their mean of hospital stay was 2 days $(\mathrm{SD}=1.2)$, and their mean monthly income was 389 JOD $(S D=177)$ (Table 1).

\section{Quality of nursing care}

Table 2 shows the individual item mean scores of the quality of nursing care for the total sample and for the two groups (who intended to revisit the hospital and who did not intend to revisit the hospital). The individual mean score was higher for the group of patients who intended to revisit the hospital.

\section{Differences between patients who intended to revisit the hospital and patients who did not intend to revisit the hospital}

Student's $t$ - test was used to examine the difference between patients who have intent to revisit the hospital and patients who did not have intent to revisit the hospital in regard to the quality of nursing care and hospital related services. The homogeneity of variances of the total score of the quality of nursing care was examined using Levene's tests. The results of Levene's tests was not significant $(P=0.07)$. Thus, the equal (pooled) variance results were assumed. The results of the Student's $t$ - test showed a statistically significant difference in scoring of quality of nursing care $(t(145)=8.001, P=0.000)$. Patients who have intent to revisit the hospital scored significantly higher $(M=3.72, S D=$ $0.60)$ than patients who did not have intent to revisit the hospitals $(M=$ $2.73, S D=0.75)$ (Table 3$)$.

\section{Discussion}

The quality of nursing care is the central theme to hospital administrators for attracting patients to their institutions. Patients' satisfaction with nursing care is well recognized as an indicator for the quality of care. There is a belief that nurse is the core element to patient's experience of hospitalization and perception of quality of care. Thus, the current study aimed at exploring patients' perception of the quality of nursing care and related hospital services among Jordanian inpatients, along with their intent to revisit the same hospital. Jordanian patients showed acceptable perception level when it comes to the quality of care; nursing care and hospital related services. Of concern, the average reported perception level (3.43/5) was consistent with the one reported by Jha [21] and Joo [22] and higher than that reported by Clark, et al. [23] but lower than the studies carried out by Jung and Youn [24] and Jung and Youn [25] and lee [20] (3.99, 3.88, 3.64, respectively). However, there were some differences in the scales, places, and sample sizes. Indeed, all the measures used five-point likert scale; however, the results can be compared indirectly.

Moreover, the average perception level of those are intended to revisit the hospital was higher than those who are not intended to revisit (3.72, 2.73, respectively). It is true that such differences in the two groups could be related to the style of nurses that provide nursing care 
Table 1. Descriptive Statistics of Demographic Characteristics $(\mathrm{N}=148)$.

\begin{tabular}{|c|c|c|c|}
\hline Variable & $\mathbf{N}(\%)$ & Range & M (SD) \\
\hline \multicolumn{4}{|l|}{ Gender } \\
\hline Females & $98(66)$ & & \\
\hline Males & $50(34)$ & & \\
\hline \multicolumn{4}{|l|}{ Educational level } \\
\hline Tawjehi & $48(32)$ & & \\
\hline Diploma & $58(39)$ & & \\
\hline Uncompleted university education & $7(5)$ & & \\
\hline Bachelor & $28(19)$ & & \\
\hline Master or higher & $7(5)$ & & \\
\hline \multicolumn{4}{|l|}{ Marital status } \\
\hline Single & $43(29)$ & & \\
\hline Married & $98(66)$ & & \\
\hline Divorced & $3(2)$ & & \\
\hline Widowed & $4(3)$ & & \\
\hline \multicolumn{4}{|l|}{ Medical Insurance } \\
\hline Private & $7(5)$ & & \\
\hline Governmental & $98(66)$ & & \\
\hline University & $14(10)$ & & \\
\hline Military & $26(17)$ & & \\
\hline Others & $3(2)$ & & \\
\hline \multicolumn{4}{|l|}{ Housing } \\
\hline City & $68(46)$ & & \\
\hline Countryside & $80(54)$ & & \\
\hline \multicolumn{4}{|l|}{ Department } \\
\hline Medical floor & $27(18)$ & & \\
\hline Surgical floor & $73(49)$ & & \\
\hline Pediatric floor & $11(8)$ & & \\
\hline Maternity floor & $37(25)$ & & \\
\hline \multicolumn{4}{|l|}{ Preference to revisit the hospitals } \\
\hline Yes & $105(71)$ & & \\
\hline No & $42(28)$ & & \\
\hline Age & & $19-70$ & $33(8.3)$ \\
\hline Hospital stay & & $1-10$ & $2(1.2)$ \\
\hline Income & & $50-2000$ & $389(177)$ \\
\hline
\end{tabular}

and in the institutional leadership. However, cultural dissimilarities in patients' perceptions of quality of care may add significance to it. The results showed that the expectations of the Jordanian patients are similar to those of Lee and Yom [8], O'connor, et al. [26] where the study participants placed the priority on the consistency of the quality of nursing care and related hospital services (e.g., number of bathrooms available, ventilation of the ward, and the quality of the bathrooms available). Indeed, You and her colleagues [27] stated that patients were more likely to rate their hospitals very high and were very pleased with nurses' communication, which made them decide to recommend their hospitals to other friends. However, the results of this study are different from those found by Lim and Tang [28], in which the study participants placed greatest emphasis on health insurance.

It was noteworthy that Jordanian inpatients' showed high expectations for hospital physical environment "ventilation of the ward" (3.7/5), "lighting condition of the ward" (3.7/5), and "condition of the area provided to eat at the ward (3.7/5)", followed by "information given by the nursing staff regarding the illness" (3.6/5), information given on facilities available when first came to the ward" (3.6/5), and "amount of information displayed at the entrance" (3.6/5), but comparatively low expectations for them to "nurses are competent" (3.1/5) and "nurses are knowledgeable enough to answer my questions" (3.1/5). Thus, it can be deemed that patients expected a lot by the quality of care in relation to hospital services, but did not expect much in terms of efforts taken by nurses for nursing competencies. Lee and Yom [8] reported the same order with slight level variations. The variation in bedside nursing care and safety environment might be controversial, but nurses are known to spend more time with their patients, which enables them to show that caring attitude through being sensitive to patients' reports of

Table 2. Descriptive Statistics of the Individual Item of the Quality of Nursing Care ( $\mathrm{N}=148)$.

\begin{tabular}{|c|c|c|c|}
\hline \multirow[t]{2}{*}{ Item } & Total & $\begin{array}{l}\text { Yes } \\
\text { Group }\end{array}$ & No Group \\
\hline & M (SD) & M (SD) & M (SD) \\
\hline 1. The way the ward staff welcomed & $3.3(0.95)$ & $3.5(0.86)$ & $2.7(0.91)$ \\
\hline 2. Care given by the nurses & $3.4(0.95)$ & $3.7(0.85)$ & $2.7(0.90)$ \\
\hline 3. Respect shown by the nurses & $3.4(0.92)$ & $3.6(0.79)$ & $2.7(0.92)$ \\
\hline 4. Courtesy of the nurses & $3.3(1.01)$ & $3.6(0.88)$ & $2.7(0.97)$ \\
\hline 5. Willingness of nurses to help when asked for help & $3.4(0.97)$ & $3.6(0.87)$ & $2.8(0.91)$ \\
\hline $\begin{array}{l}\text { 6. The way nurses understood emotions and gave } \\
\text { comfort during stay }\end{array}$ & $3.4(1.00)$ & $3.7(0.89)$ & $2.7(0.91)$ \\
\hline 7. Opportunity given to express concerns leisurely & $3.4(0.79)$ & $3.6(0.83)$ & $2.7(0.65)$ \\
\hline 8. The nurses' response to needs & $3.4(1.01)$ & $3.6(0.88)$ & $2.7(0.94)$ \\
\hline 9. Concern shown by nurses towards illness & $3.4(1.01)$ & $3.6(0.87)$ & $2.7(1.1)$ \\
\hline 10. Friendliness of nurses & $3.3(1.01)$ & $3.6(0.90)$ & $2.7(1.1)$ \\
\hline $\begin{array}{l}\text { 11. Nurses treated me in a way that made me feel } \\
\text { important }\end{array}$ & $3.2(1.11)$ & $3.4(0.94)$ & $2.5(1.1)$ \\
\hline 12. Nurses spent adequate time with me & $3.2(1.11)$ & $3.5(0.95)$ & $2.5(1.1)$ \\
\hline $\begin{array}{l}\text { 13. The nurses gave me treatment/medicine without } \\
\text { any delay }\end{array}$ & $3.3(1.11)$ & $3.6(0.98)$ & $2.5(1.0)$ \\
\hline 14. The nurses maintained records efficiently & $3.4(1.01)$ & $3.63(0.95)$ & $2.7(0.96)$ \\
\hline $\begin{array}{l}\text { 15. Efforts taken by nursing staff to provide peaceful } \\
\text { environment in the ward }\end{array}$ & $3.3(1.01)$ & $3.6(0.94)$ & $2.6(0.91)$ \\
\hline 16. Frequency of visits paid to me by the nursing staff & $3.3(1.11)$ & $3.5(0.99)$ & $2.6(0.9)$ \\
\hline 17. No. of nurses available for my care & $3.3(1.11)$ & $3.5(1.0)$ & $2.6(1.0)$ \\
\hline $\begin{array}{l}\text { 18. The nurses maintain good coordination with other } \\
\text { staff }\end{array}$ & $3.3(1.01)$ & $3.5(0.96)$ & $2.7(0.99)$ \\
\hline $\begin{array}{l}\text { 19. Efforts taken by the nursing staff to minimize } \\
\text { delay in performing investigations }\end{array}$ & $3.3(1.11)$ & $3.6(0.99)$ & $2.7(0.97)$ \\
\hline $\begin{array}{l}\text { 20. Efforts taken for ensuring privacy during } \\
\text { examination }\end{array}$ & $3.3(1.11)$ & $3.6(1.0)$ & $2.7(1.1)$ \\
\hline 21. Provisions for an un-disturbed sleep & $3.4(1.11)$ & $3.8(0.87)$ & $2.7(1.1)$ \\
\hline 22. The quality of the bed & $3.6(0.96)$ & $3.8(0.75)$ & $2.9(1.00$ \\
\hline 23. The quality and cleanliness of bed linen & $3.6(1.01)$ & $3.9(0.79)$ & $2.8(1.1)$ \\
\hline 24. No. of bathrooms available & $3.6(1.01)$ & $3.9(0.82)$ & $2.9(1.1)$ \\
\hline 25. Quality of the bathrooms available & $3.5(1.11)$ & $3.7(0.94)$ & $2.9(1.2)$ \\
\hline 26. Cleanliness of the toilets & $3.5(1.11)$ & $3.7(0.96)$ & $2.4(1.1)$ \\
\hline $\begin{array}{l}\text { 27. information given on facilities available when first } \\
\text { came to the ward }\end{array}$ & $3.6(1.01)$ & $3.9(0.71)$ & $2.8(1.1)$ \\
\hline $\begin{array}{l}\text { 28. Information given by the nursing staff regarding } \\
\text { the illness }\end{array}$ & $3.7(1.01)$ & $4.0(0.74)$ & $2.8(1.2)$ \\
\hline $\begin{array}{l}\text { 29. Information given by the nursing staff on } \\
\text { investigations }\end{array}$ & $3.6(1.11)$ & $3.9(0.80)$ & $2.8(1.2)$ \\
\hline 30. Ventilation of the ward & $3.7(1.01)$ & $4.0(0.76)$ & $2.9(1.1)$ \\
\hline 31. Lighting condition of the ward & $3.7(1.01)$ & $4.0(0.76)$ & $2.9(1.1)$ \\
\hline 32. Condition of the area provided to eat at the ward & $3.7(0.97)$ & $4.0(0.75)$ & $2.9(1.1)$ \\
\hline 33. Amount of information displayed at the entrance & $3.6(1.01)$ & $3.9(0.77)$ & $2.9(1.1)$ \\
\hline 34. The signs of direction for wards/labs & $3.7(1.01)$ & $3.9(0.82)$ & $3(1.2)$ \\
\hline 35. Nurses are competent & $3.1(1.31)$ & $3.4(1.11)$ & $2.2(1.1)$ \\
\hline $\begin{array}{l}\text { 36. Nurses are knowledgeable enough to answer my } \\
\text { questions }\end{array}$ & $3.1(1.01)$ & $3.5(1.12)$ & $2.3(1.1)$ \\
\hline Total & $\begin{array}{c}3.43 \\
(0.79)\end{array}$ & $\begin{array}{c}3.72 \\
(0.62)\end{array}$ & $\begin{array}{c}2.73 \\
(0.75)\end{array}$ \\
\hline
\end{tabular}

Table 3. Student's T-Test of Quality of Nursing Care. ${ }^{* *}$ Significant at $P<0.01$

\begin{tabular}{|c|c|c|c|c|}
\hline \multirow{2}{*}{ Variable } & Quality of nursing care & \multicolumn{3}{|c|}{ Student's $\boldsymbol{t}$ - test } \\
\cline { 2 - 5 } & M (SD) & $\boldsymbol{d f}$ & $\boldsymbol{t}$-value & $\boldsymbol{P}$-value \\
\hline Yes $(\mathrm{n}=106)$ & $3.72(0.62)$ & 145 & 8.001 & $0.000^{* *}$ \\
\hline No $(\mathrm{n}=42)$ & $2.73(0.75)$ & & & \\
\hline
\end{tabular}


quality of nursing care giving that nurses are working in a demanding environment $[29,30]$.

The quality of bedside nursing care is constantly affected by the related hospital services such as the quality of beds, the quality and cleanliness of bed linens, the number of bathrooms available, the quality of the bathrooms available, cleanliness of the toilets, and ventilation and lighting in the wards. The results of this study revealed that the availability of those services had a significant impact on patient's satisfaction with nursing care. This could be because the related hospital services allow nurses to spend more time for direct patient care. Such results are congruent with those reported in literature [19,31] investigated inpatients' quality of care satisfaction and found a strong relationship with the relevant hospital services such as nutritional care, room atmosphere, procedure of incoming patients, room cleanliness, and cafeteria and parking. Therefore, the quality of nursing care was perceived by patients as being poor, but the other related services were perceived as superior.

Meanwhile, it is surprising to note that the mean for the related hospital services was below the average in both groups. This finding obviously showed that the related hospital services continue to be the most serious problems facing Jordanian hospitals. Thus, the healthcare administrators need to apply urgent interventions to improve the surrounding environment in Jordanian hospitals.

However, the difference in the expectations between those with the intent to revisit the same hospital $(\mathrm{M}=3.72, \mathrm{SD}=0.62)$ and those who do not have the intent $(\mathrm{M}=2.73, \mathrm{SD}=0.75)$ is large. So, the 36 items comprising the nursing services and the other health related services indicated a significant statistical difference between the two groups. These results may have indicated that patients who are willing to revisit the hospital were satisfied with quality of care provided by the nurses and other allied professionals. However, some exaggeration by the study sample might be there because of the variation in health insurance or they may have appreciated any care given to them. Indeed, the association between the quality of nursing care, and other related hospital services, and intent to revisit the same hospital showed a high significant positive relationship $(\mathrm{r}=0.56, \mathrm{p} \leq 0.01)$. Therefore, nursing directors and healthcare administrators should have great influence on the service quality. Also, they should focus on nurses' satisfaction that would guarantee better provision of higher quality nursing services [29,32]. Moreover, the perceived quality of care by patients who had no intent to revisit the hospital was relatively low, resulting in poor quality of care. This strongly suggests that directors of nursing should be constantly implementing and supervising quality management programs.

The current study shows that quality of nursing care and related hospital services still continues to be a problem within the Jordanian hospitals. Despite the high levels controversial talk in press and nursing conferences, Jordanian patients still report being satisfied with the quality of care. This confirms the contradiction that is well documented in the literature, and supports the recommendations of applying the caring attitude to promote patients' satisfaction with quality of care [3335]. Therefore, nurses need to be aware of their ways of approaching patients and their families. In addition, healthcare institutions need to focus more on patient satisfaction as an indicator for quality of care. However, the authors encourage healthcare administrators and directors of nursing to broaden their approaches to quality of care and related hospital services. As different cultures have different perception of quality of care, the authors hope that this study will open the gate for more quantitative and qualitative studies to be conducted. Since the findings of the current study are based on the exploration of only Jordanian patients, the generalizability is limited. Additional research using different methods and sample techniques would be helpful in order to enhance the generalizability.

\section{Conclusion}

The perceived quality of care and related hospital services by patients were relatively low, resulting in poor nursing care. Therefore, directors of nursing should be constantly implementing quality management in order to provide high quality services. In addition, hospital administrators should have more efforts to modify hospital environment. Finally, this study is providing the regional and national researchers with a valid and reliable measurement for further investigation.

\section{Funding}

The authors have no funding of conflicts of interest to disclose.

\section{Acknowledgements}

The authors express their appreciation to all patients who participated in this study. Also, thanks extended to the directors of nursing and hospital administrators.

\section{References}

1. Törnvall E, Wilhelmsson S (2010) Quality of nursing care from the perspective of patients with leg ulcers. $J$ Wound Care 19: 388-395. [Crossref]

2. Zhao SH, Akkadechanunt T, Xue XL (2009) Quality nursing care as perceived by nurses and patients in a Chinese hospital. J Clin Nurs 18: 1722-1728. [Crossref]

3. Hoodless M, Bourke L, Evans F (2008) Quality of rural primary health care: Including the consumer. Australian Journal of Primary Health 14: 82-88.

4. Tang W, Soong C, Lim W (2013) Patient satisfaction with nursing care: A descriptive study using interaction model of client health behaviour. International Journal of Nursing Science 3: 51-56.

5. Chahal H, Kumari N (2012) Service quality and performance in the public health-care sector. Health Mark Q 29: 181-205. [Crossref]

6. Henoch I, Lovgren M, Wilde-Larsson B, Tishelman C (2011) Perception of quality of care: comparison of the views of patients' with lung cancer and their family members Journal of Clinical Nursing 21: 585-594.

7. Fung C, Mercer S (2009) A qualitative study of patients' views on quality of primary care consultations in Hong Kong and comparison with the UK care measure. Family Practice 10: 10

8. Lee M, Yom Y (2007) A comparative study of patients' and nurses' perceptions of the quality of nursing services, satisfaction and intent to revisit the hospital: A questionnaire survey. International Journal of Nursing Studies 44: 545-555.

9. Bassett C (2002) Nurses' perceptions of care and caring. Int J Nurs Pract 8: 8-15. [Crossref]

10. Kvale K, Bondevik M (2010) Patients' perceptions of the importance of nurses' knowledge about cancer and its treatment for quality nursing care. Oncology Nursing Forum 37: 436-442.

11. Isaac T, Zaslavsky A, Cleary P, Landon B (2010) The relationship between patients' perception of care and measures of hospital quality and safety. Health Services Research 45: 1024-1039.

12. Radwin LE, Farquhar SL, Knowles MN, Virchick BG (2005) Cancer patients' descriptions of their nursing care. J Adv Nurs 50: 162-169. [Crossref]

13. Riccio PA (2000) Quality evaluation of home nursing care: perceptions of patients, physicians, and nurses. Nurs $A d m Q 24:$ 43-52. [Crossref]

14. Alhusban MA, Abualrub RF (2009) Patient satisfaction with nursing care in Jordan. $J$ Nurs Manag 17: 749-758. [Crossref]

15. Ahmad MM, Al-Daken LI, Ahmad HM3 (2015) Quality of Life for Patients in MedicalSurgical Wards. Clin Nurs Res 24: 375-387. [Crossref] 
16. Darawad MW, Al-Hussami M, Saleh AM, Al-Sutari M (2014) Jordanian patients' satisfaction with pain management. Pain Manag Nurs 15: 116-125. [Crossref]

17. Jordan Statistics Department (2012) Jordan statistical year book, department of statistics.

18. Faul F, Erdfelder E, Lang A, Buchner A (2007) G*Power 3: a flexible statistical power analysis program for the social, behavioral, and biomedical sciences. Behaviour Research Methods 39: 175-191.

19. Senarath U, Gunawardena N (2011) Development of an instrument to measure patient perception of the quality of nursing care and related hospital services at the national hospital of Sri Lanka. Asian Nursing Research 5: 71-80.

20. Lee M (2003) A study of the nursing service perceived by consumers and providers, and the tool that measures nursing services. Journal of Korea Academy of Nursing 33: $772-783$

21. Jha AK, Orav EJ, Zheng J, Epstein AM (2008) Patients' perception of hospital care in the United States. N Engl J Med 359: 1921-1931. [Crossref]

22. Joo M (2001) A study on the determinations of consumers oriented nursing service quality - SERVQUAL model based. Doctoral Dissertation. The Seoul National University of Korea, Seoul, unpublished.

23. Clark P, Leddy K, Drain M, Kaldenberg D (2007) State nursing shortages and patien satisfaction: more RNs, better patient experiences. Journal of Nursing Care Quality 22: 119-129.

24. Jung W, Yoon S (2003) Customer satisfaction on the nursing service: a relationship among the expectation and the perceived performance and the willingness of reuse of patients on the nursing services. Journal of Korea Academy of Nursing Administration 9: $31-40$

25. Jung M, Youn M (2001) A study on the consumer's expectation, perception, quality, and satisfaction with the industrial nursing service. Journal of Korea Community Nursing 12: 570-581.
26. O'connor S, Trinh H, Shewchu R (2000) Perceptual gaps in understanding patient expectations for health care service quality. Heath Care Management Review 25: $32-38$

27. You L, Aiken L, Saloane D, Liu K, He G, et al. (2013) Hospital nursing, care quality, and patient satisfaction: cross-sectional surveys of nurses and patients in hospitals in China and Europe. International Journal of Nursing Studies 50: 154-161.

28. Lim PC, Tang NK (2000) A study of patients' expectations and satisfaction in Singapore hospitals. Int J Health Care Qual Assur Inc Leadersh Health Serv 13: 290299. [Crossref]

29. Al-hussami M, Darawad M, Saleh A, Hayajneh F (2013) Predicting nurses' turnover intentions by demographic characteristics, perception of health, quality of work, and work attitudes. International Journal of Nursing Practice 20: 79-88.

30. Darawad M, Nawafleh H, Maharmeh M, Hamdan-Mansour A, Azzeghaiby S (2015) The relationship between time pressure and burnout syndrome: A cross-sectional survey among Jordanian nurses. Health 7: 14-22.

31. Bacon C, Mark B (2009) Organizational effects on patient satisfaction in hospital medical-surgical units. The Journal of Nursing Administration 39: 220-227.

32. Saleh A, Darawad M, Al-Hussami M (2014) Organizational commitment and work satisfaction among Jordanian nurses: A comparative study. Life Science Journal 11 $31-36$

33. Darawad M, Al-hussami M, Saleh A, Al-sutari M, Mostafa W (2014) Predictors of ICU patients' pain management satisfaction. Australian Critical Care 28: 129-133.

34. http://www.dos.gov.jo/dos_home_a/main/yearbook_2012.pdf

35. Yildlz Z, ErdoÄŸmuÅŸ S (2004) Measuring patient satisfaction of the quality of health care: a study of hospitals in Turkey. J Med Syst 28: 581-589. [Crossref]

Copyright: $\ 2017 \mathrm{Al}-\mathrm{Hussami}$ M. This is an open-access article distributed under the terms of the Creative Commons Attribution License, which permits unrestricted use, distribution, and reproduction in any medium, provided the original author and source are credited. 